\title{
Exploring Relations between Watchers and Watched in Control(led) Systems: Strategies and Táctics*
}

\author{
Gavin J .D. Smith1
}

\begin{abstract}
Using ethnographic observation within a number of Closed Circuit Television (CCTV) control rooms as evidence, this paper documents the apparently trivial but subjectively meaningful types of technologically mediated interaction taking place between CCTV operators and those watched. It examines the operators' interpretations of the various incidents, individuals and social realities observed. In so doing, the author suggests a number of interesting social-phenomenological processes are occurring. These include: the formation and existence of disembodied relationships between watchers and watched across distanciated CCTV surveillance networks; an operator gaze incorporating care, control and creativity; the existence of hermeneutical narrative constructions among the operators. The latter practice can be empirically demonstrated through the operators' creation of 'celebrity characters', their attribution of pseudo-identities for cameo 'guest stars' and their playful characterisation of the framed action taking place in the spaces under observation. It is argued that such informal tactics, employed to both entertain and relieve pressure, are the unintended outcome of systemic strategies of control designed to induce conformity. They allow the operators to make sense of, bring meaning to and cope with relentless, often disjointed, imagery and with the emotional strain of the CCTV workplace culture. The paper also suggests that tactics are not limited to the watchers. The watched or Stars of CCTV appear to employ methods in a similar bid to manoeuvre themselves around the cameras. By considering the practices of watchers and watched, it is argued more generally that CCTV technology is a social medium, the people, places and objects watched functioning not simply as passive 'objects of information', but also as active 'subjects of communication'.
\end{abstract}

\footnotetext{
* The author extends immense thanks to his mentor, Dr Chris Wright, who always (and selflessly) provides time, space and energy for the sounding out of ideas. He affords each and every discussion with immeasurable insight and input. Enormous gratitude is due to Norma Smith for proofreading earlier drafts. The author also wishes to thank the Economic and Social Research Council (ESRC) for financing the research (award number PTA-030-2002-00893). Last, but by no means least, significant indebtedness is owed to all of the operators and gatekeepers who participated in the research and who gracefully tolerated the author's 'inquisitive' presence in their world of work.

${ }^{1}$ Department of Sociology, University of Aberdeen, UK. mailto:g.j.d.smith@abdn.ac.uk
} 


\section{Introduction}

CCTV cameras are now a dominant feature of the UK's socio-cultural and spatial landscape, yet detailed academic observational studies into the operational diversity of such systems of surveillance generally remain in short supply. Although a critical literature based around 'control room operation' exists, it centres itself on one of three 'classical' strands: on the formal and informal functioning of differing CCTV systems, that is, who is behind the screens, who/what is targeted and why (Norris and Armstrong, 1999; McCahill, 2002; McCahill and Norris, 2003; Lomell et al., 2003; Smith, 2004); on dominant themes of operator stereotyping, targeting inequalities, power differentials and processes of social exclusion (Norris and Armstrong, 1999; McCahill, 2002; Lomell et al. 2003; Lomell, 2004); and, less critically, on characterising the job of CCTV operator and identifying strategies to improve operator productivity, output and consequent system effectiveness (Helten and Fischer, 2003; Loveday and Gill, 2003; Gill and Spriggs, 2005a; Gill et al., 2005b).

As a result, limited knowledge and social theory exist in a vast conjectural vacuum which has many rich, empirically grounded theoretical areas awaiting exploration. The following, for example, are relatively uncharted issues: the social significance of timespace compressed, technologically mediated interactions which occur and relations which form between observer and observed (Giddens, 1990); the ways in which operators make sense of and bring meaning to the simulated, televisual world they are locked within; the assumption that those disproportionately subjected to the CCTV facilitated gaze are indubitably disempowered.

Influenced by ethnomethodology and the cultural populism ideas of De Certeau (1984), this paper touches empirically upon such areas, showing how watchers and (to a lesser extent) watched appear to respond to the gaze(s) produced by televisual screen and CCTV camera in more creative, subversive and 'entrepreneurial' ways than hitherto documented. From the contextual confines of the 'control' room (or 'room of control' as I like to term it), particular attention is given to the dual nature of this specific human-technology interaction and the various outcomes (Latour, 1999). To this end, a brief consideration of the relevant CCTV literature is firstly given, enabling a rationale for the present paper to be identified. Attention is then paid to the methodological approach taken, detailing how and where the observations were carried out, along with the analytical scheme adopted, before the main findings of the research are presented and discussed. The paper is concluded with the argument that the actual relations and interactions between watchers and watched are more complex than previously documented and, as such, detailed empirical research with those subject to a particular CCTV gaze and a reconceptualisation of their role in surveillance studies, is urgently required.

\section{Situating the Study - the watched as 'objects of information'}

Whilst there is a relative shortage of qualitative research on CCTV control room operation, what does exist is generally of high quality. In particular, two 'classics' in the field stand out, namely Norris and Armstrong's (1999) landmark in-depth observational 
study of three open-street public space CCTV systems and McCahill's (2002) research conducted within two shopping malls and at an industrial workplace. These studies remain the benchmark from which any ethnographic investigation of CCTV must presently be measured. That said, over the past few years, a steady, robust and cross cultural stream of micro studies have emerged on CCTV operation, with a range of further locales being brought into consideration; most notably a higher education campus's monitoring facility (Smith, 2004), a police cell block (Newburn and Hayman, 2001), several retail CCTV systems (Loveday and Gill, 2003), various local authority systems in the UK (Goold, 2003; 2004; Neyland, 2006a \& 2006b; Smith, 2007), Milan (Fonio, 2007) and Mexico (Botello, 2007), an open-street, shopping mall and major transport centre in Oslo (Lomell, 2004), a Dutch railway company (Dubbeld, 2005) and two shopping centres in Berlin (Helton and Fischer, 2003; Helton and Fischer, 2004). This empirical research has not appeared in isolation. Rather, connected to the above studies is a more interdisciplinary, critical theoretical literature. This focuses attention on the perceived insidious commodification and privatisation of public space and the moral order by neoliberal agencies, and the various implications these developments have for a minority of 'flawed consumers' who are either unable or unwilling to participate and conform to the ever exclusive rules and dress code of increasing 'theme park' style cities (Bannister et al., 1998; Bauman, 1998; Reeve, 1998; Coleman, 2004).

I intend to show that the empirical and theoretical literatures are linked through their general conception of watchers as empowered and prejudicial 'agents', watched as passive, disempowered 'objects'. The former group are furnished with control, the latter group the subject(s) of control. So as to make this connection more apparent, some of the central findings emerging from the aforementioned observational studies will be outlined, before attention is turned to a consideration of the theoretical literature.

\section{Research on CCTV control room operation}

One of the major concerns of the observational research to date relates to who and what is 'surveilled' by CCTV operators in differing institutional settings and, crucially, why this is so. It has been conclusively shown that suspicion is socially constructed, CCTV operators predominantly targeting and associating criminality with young working class males (Norris and Armstrong, 1999; McCahill, 2002; Smith, 2004). Indeed, Norris and Armstrong (1999) found in their observational study of three public space systems that $93 \%$ of targeted surveillances were directed toward males, $85 \%$ of whom were in their teens or twenties, usually wearing distinctive sub-cultural style clothing such as baseball caps, shell suits and 'hoodies'. They argue that such individuals were chosen primarily on the basis of the operators' negative attitude to male youth in general, and black youth in particular. Similarly, those considered to be 'matter out of place' (Douglas, 1991), for example drunks, beggars, street traders, gangs and the homeless, in the consumer dominated streets, were all subjected to concentrated surveillance. The two conclude in a separate article that:

[T]he gaze of the cameras does not fall equally on all users of the street but on those who are stereotypically predefined as potentially deviant, or who, through appearance and demeanour, are singled out by operators as unrespectable. In this way youth, particularly those already socially and 
economically marginal, may be subject to even greater levels of authoritative intervention and official stigmatisation, and rather than contributing to social justice through the reduction of victimisation, CCTV will merely become a tool of injustice through the amplification of differential and discriminatory policing. (1997: 8)

Echoing these findings, McCahill's (2002) study of two shopping malls found that males constituted $71 \%$ of targeted surveillances, $88 \%$ being in their teens or twenties. Lomell (2004: 351) has also shown in her research that in 'all three systems [observed], drug addicts/scruffies were the main object for targeting' and then, frequently, physical removal. Similarly, research conducted by Neyland (2006a) found that it was groups of young people, particularly those immobile, appearing static on the camera or 'hanging about', which operators felt had either the highest propensity to commit anti-social acts or posed the greatest nuisance to the 'flow' of consumerism. Clearly, therefore, it would seem that appearance, limited cultural capital and behaviour as defined by reality constructing CCTV operators, are crucial mechanisms affecting one's propensity to receive surveillance whether moving through or being stationary within particular spaces.

A second major area of investigation has focussed on the human mediation of surveillance technologies and the various social relations which shape the everyday operational dynamics of CCTV. Such discourse highlights the importance of individualised (often informal) cultural factors at play within CCTV workplaces, especially those which lead operators to either misuse, sabotage or neglect localised systems of surveillance, thus undermining their wider effectiveness (McCahill and Norris, 2003; Smith, 2004). McCahill and Norris's (2003) study of South London Shopping Mall CCTV system demonstrated, for example, that the level of organisationally-induced conflict between security officers and middle management, and between security officers and the local police force, had created both a divided and disillusioned workforce. The upshot of this, they argue, was that the cultural dynamic of the locale, combined with the differing personal characteristics and goal orientations of each security guard, led to a general 'non-use' of the CCTV system. Norris and Armstrong (1999) have also found the level of operator integration within other agencies of control - such as the police - a crucial determinant factor behind quick and successful embodied deployment. As they show, some sites were less integrated than others. Another example of the social processes underpinning CCTV operation can be seen in McCahill's (2002) research, which revealed how management's use of the cameras to monitor and control employees was undermined and resisted by security staff and lower level workers due to their shared class identity. The former, socially, had more in common with and greater sympathy toward their equivalently paid colleagues and their informal practices than they did with the goals and actuarial controlling strategies implemented by a top heavy management. Smith's (2004) study of college campus CCTV operators also shows that strained social relations between employers and employees, combined with the structurally-produced alienation, boredom and monotony of watching televisual images for hours on end with limited financial and psychological gain, resulted in operator resistance and overall system dysfunction as shown in the way such individuals used the system to play games of 'hide and seek' (p389).

Thus, the ways in which CCTV systems operate is highly 'context dependent' and 
affected significantly by the existing workplace culture, implying that:

One cannot make any generalisations about the extent, nature and impact of CCTV surveillance from the mere existence of a system. CCTV systems have diverse operating procedures, staffing policies and levels of technological sophistication. (McCahill and Norris, 2003: 44)

A third area of observational research focuses on control room design and ergonomics and, as such, is more action-orientated and psycho-administrative in content. It considers CCTV's operationally multi-tasked nature and ways of improving CCTV operator output (Loveday and Gill, 2003). Helten and Fischer's (2004) research in Berlin shopping malls, for example, shows that fire prevention, property management, coordinating the activities of the workers and car park administration, as opposed to explicit social control, sit higher on day-to-day, managerial operational agendas. They describe, for example, how handling alarms, parking barriers and door entry systems, along with health and safety concerns, form the basis of an operator's day rather than monitoring and targeting certain social groups with the cameras. Indeed, the two write that usage of CCTV in this way was 'rare' (p31).

\section{CCTV and theories of power, discipline and social exclusion}

\section{CCTV and the consumer city}

As a key tool in the politics of vision, cameras in the cities of the UK are helping to put into effect what can and cannot be seen on the streets. (Coleman, 2004: 301)

As outlined, the key observational studies highlight the existence of institutionalised prejudice amongst the operators and its socially significant implications, and the importance of the workplace culture on CCTV operation. As the above quote clearly relays, the related issue of 'socio-spatial cleansing' is the main driver of the theoretical literature. The rapid rise of CCTV in the United Kingdom is, for some, closely bound up with a wider civilizing process agenda of urban regeneration and the tighter management, regulation and recasting of space as a site for mass consumption and economic profit (Reeve, 1998) This process has been driven by the formation of robust neo-liberal partnerships and Town Centre Management (TCM) schemes, primarily involving a mixture of public/private sector representatives from local councils and police authorities, cultural and educational institutions, businesses and the media. Such key players work closely together in a highly rationalised fashion, exchanging information and sharing resources, so as to clean up 'urban decay', impact upon rising crime rates and attract inward investment (Coleman, 2004). Indeed, in a bid to stave off business competition from nearby metropolitan competitors, safety, predictability, spatial control, pacification and the creation of city 'leisure centres' have come to the forefront of such primary definers' concerns. CCTV is key to this process, the cameras perceived as helping to facilitate and instil an emotionally charged 'feel-good' safety factor in the hearts and minds of the general public, whilst being able to quickly locate any form of civil disorder or disobedience threatening the tranquillity of the shopping experience or hedonistic thrill 
of the night-time economy.

\section{CCTV technologies as facilitating social exclusion}

CCTV disproportionately surveys and casts suspicion on the poor in the spaces of the city centres and in the estates outside the city. (Coleman, 2004: 302)

Various commentators fear that CCTV technology has emerged not so much for its crime control function, but rather to target, monitor and exclude a number of social 'undesirables' whose appearance threatens the very image of the commercial city:

As surveillance cameras routinely monitor the street prohibitions of the neoliberal city, they also reinforce the moral codes, intolerances and normative prescriptions of its creators ... [with] certain forms of culture increasingly subject to oppressive monitoring and curtailment. (Coleman, 2004: 301)

Among such 'flawed consumers' are beggars, the homeless, prostitutes, street traders and gangs of youths. Their mere presence, according to one TCM spokesman, 'is a nuisance to those who want to use the streets and shopping centres in a more conventional way' (quoted in Graham and Marvin, 1996: 20), in other words, consumers wishing to spend money. Indeed, a number of TCM groups have brought in local by-laws and anti-social behaviour orders (ASBOs) legally empowering them to disperse gangs of 'rowdy' youths, and remove drunks, beggars and the homeless from their present location on the high street to the periphery of the city (Reeve, 1998). Writers such as Bannister et al. (1998) cite the work of Norris and Armstrong to claim that TCM schemes, in order to facilitate this control over space, are using CCTV surveillance in a racially and ethnically discriminatory manner. As Reeve (1998: 84) rather pessimistically concludes, 'to create a safe shopping and leisure environment [nowadays] is to be socially exclusive’.

The empowered electronic gaze

At a more micro-interactional level, other writers theorise that the introduction of CCTV cameras to monitor city centre streets electronically has fundamentally altered the nature of interaction and wider social relations between the watching state authorities and observed citizenry. For Norris and Armstrong (1998), the form of 'one-way' monitoring enjoyed by contemporary CCTV staff affords such watchers both a legitimated and enhanced voyeuristic power unmatched by any previous urban authority or embodied citizen. Facilitated by technological mediation, an authoritarian gaze that was once historically embodied and face-to-face, has now become distanciated, disembodied and anonymous (i.e. physically removed - Giddens, 1990). They argue (p5): 'the difference between the unmediated gaze of the eyes, and the camera mediated gaze of the CCTV operator, [lies in] the profound asymmetry of power inherent in CCTV monitoring ... [in that] the veil of the camera denies the possibility of a reciprocal exchange of visual data', thus placing the operator in a distinctly empowered, disciplinary position to follow, track and potentially exclude those individuals perceived to be 'out of place or out of time'. Therefore CCTV observation, it is claimed, precludes the possibility of the person observed directly questioning and challenging the watcher and this very process produces 
an uneven, unilateral power imbalance between the two (Dubbeld, 2003). So whilst camera operators can freely choose to monitor in close detail who and what they like (a seemingly clear indicator of power), they themselves cannot be seen, are relatively unaccountable for their gaze and remain, in a corporeal sense, absent (Dubbeld, 2003). ${ }^{2}$ From this point of view, the watched are passive objects, the watchers empowered voyeurs, uniquely equipped with both the technological and subjective capacity to effectively define reality (Giddens, 1984). By apparently quashing the need for any kind of customary human contact, CCTV might be seen as a unique technological form of control fundamentally removing the traditional 'social' prefix.

\section{CCTV technologies as facilitating interaction?}

It is at this point that a rationale for my study can be identified. As shown, most macro theoretical commentators view the introduction and operation of CCTV as being tied to an exclusionary neoliberalist regeneration agenda. The micro observational literature, whilst being more empirically informed, remains preoccupied with a similar 'social sorting' theme, documenting the disproportionate targeting of the 'usual suspects' and hypothesising the subsequent disempowerment, discipline and stigmatisation personally suffered (Lyon, 2003). Whilst much value underpins the two discourses, the aim of this paper is to critically analyse the assumptions and contentions concealed within both by asking the question, does the actual operation of CCTV follow as instrumental and rational a trajectory as is presently contended? Is the watchers relationship with the watched based simply upon unilateral domination? Or, does the CCTV operator's very subjectivity and placement within a system of dual control, combined with the appearance of dynamism, entrepreneurialism and resistance on the part of the watched, mean that the everyday practice of surveillance is characterised by greater complexity? In short, the aim of this paper is the return to surveillance studies of a distinctly social frame of analysis (Latour, 2005). It is here that De Certeau's (1984) classic distinction between 'strategies' and 'tactics' is important.

De Certeau defines strategies as being the various ideological and physical (structural) ways in which the established power elite attempt to shape and control populations in order to induce conformity; in this case through CCTV camera networks, police and security personnel, public-private sector partnerships, radio links, by-laws, intelligence databases at one level, and through the rules and structure which govern the operators' practices at another. Designed for predictability and to manage the behaviour of people, strategies in practice produce a range of unintended outcomes. One such effect, claims De Certeau, is the development of actor-created 'tactics'. Such practices emerge from the ways in which individuals consciously and subconsciously interpret, interact with and react to such systemic schemes. Tactics can involve the individual accepting or complying with the strategy, learning to evade and manoeuvre themselves around its intended properties or taking advantage of the 'unintentional opportunities' strategies produce, subverting and exploiting the system's various 'cracks' (a process called 'reappropriation'). For De Certeau, both 'street life' and 'work life' place individuals in a

\footnotetext{
2 An important weakness regarding this argument is that an increasing number of CCTV operators are now being summoned to provide expert witness evidence in Court a propos the footage captured, thus losing their crucial anonymity privilege (Smith, 2008a).
} 
constant, conscious and subconscious struggle against the various institutions, rules and power structures which compete to influence their behaviour. Yet by their very controlling nature, the two forms of existence actually have the unintended effect of thrusting into action the human spirit's creative energies and determination, leaving ever unpredictable the micro outcome of such a battle. Thus De Certeau's analytical conceptualisation of struggle provides the forthcoming discussion with a useful theoretical framework for contextualising the roles, placement and relations between watchers and watched, the two being controlled in differing ways both by one another's actions and by the very system facilitating their interaction. It affords explanatory space for the interactional ambiguities and existence of meaningful defiance intrinsic to systems of surveillance. Such a terminology helps portray both watchers and watched as being controlled-dissenters locked within a continuous two dimensional conflict, each agent producing a range of interesting tactical responses.

\section{Methods}

Institutional ethnography is apposite for inquiring: surveillance activities involving various forms of texts existing in a circuit of surveillance involving human surveillance agents at one end of the circuit and human surveillance subjects at the other. (Walby, 2005: 161)

A fundamental impetus behind this paper relates to Walby's (2005) plea for institutional ethnography (IE) to be utilised by more surveillance scholars:

Surveillance researchers should focus on the text-mediated interactions made between surveillance agents and surveillance subjects at various points of contact in the surveillance circuit. (170)

As suggested, the method involves a detailed examination of material surveillance 'texts', that is, 'the words, images, or sounds that are set into a durable material form of some kind that can then be read, seen, heard, or watched' (160) within the 'contact areas' of surveillance sites; in this case, the electronic images and information the CCTV cameras and televisual monitor screens portray, which effectively link watchers and watched in CCTV rooms of control. Yet the approach realises the importance of agency and the socially significant ways in which images are interpreted by active CCTV operators:

IE as method is important because it situates individuals in the complexity of their lived realities and draws from their experiential knowledge of those realities to show how sequences of texts coordinate actions, consciousness, and forms of organization extra-locally. (164)

But IE goes further than this in considering what becomes of texts as they get sent, interpreted, stored and acted upon across wider ranging institutional surveillance circuits. It is not the aim of this paper to partake in such a far reaching task. Indeed, there are problems with taking an IE approach. In a surveillance context, these include a demand on the researcher to take the standpoint of the 'surveillance subject' which, in my view, 
and contrary to Walby's conception it would seem, includes both those on the street ${ }^{3}$ and those in the CCTV room of control (as the practices of both are subject to monitoring and control, which in turn produce emotionally charged states of being). Moreover, such a research style perhaps tends to over-fetishize the organizational arrangement and power of the institution to shape subjectivities, overlooking the importance of a traditional ethnographic and ethnomethodological approach with its ability to pick up on the idiosyncratic and complex nature of respondents' micro non-work selves and accounts, and the effects of such identities on job performance.

Despite limitations, enlightenment was taken from the central IE position that it is precisely the text-mediated interactions which connect surveillance agents (in my view, also subjects) and subjects (in the conventional surveillance usage). The influence of this specific methodology can be felt throughout this paper.

So as to generate the substantive data required for a discussion of the questions and issues raised above, detailed ethnographic research, connected to a $\mathrm{PhD}$ doctoral study, was carried out. This involved conducting, at differing times, days and months of the year, over 300 hours observation within a UK-wide sample of locales including: four public space local authority systems; three shopping malls; three major transport centres; a hospital; a supermarket; and a football stadium. ${ }^{4}$ The research combined fleeting 'flashlight' (i.e. short, one-off) visits to some of the sites, with lengthy, prolonged and extensive immersion within others. Despite finishing with a relatively healthy list of research settings, negotiating access in the beginning was a lengthy and particularly frustrating process, many of the initial locales contacted quick to either ignore or decline my application letters, emails and telephone calls. ${ }^{5}$ Eventually, at a time when cynical thoughts were distinctly circulating, persistence paid off, admission being granted to a police-run public space system. Rapport was quickly built with a particularly helpful, friendly and understanding site gatekeeper who subsequently acted as an extremely obliging sponsor, negotiating my successful entrée into each of the aforementioned settings. Immense gratitude is due to this individual. All of the ethnographic narratives presented in this paper were the result of 'shadowing' particular operators, noting down in as much detail as was possible what they talked about, what they looked at and how they dealt with situations and performed their job. Sincere thanks also go to them.

My observational role within each site researched was very much as background 'sociological voyeur', caught within three detached, yet technologically interconnected realities: the embodied, perceptual action and behaviours occurring within the room of control; the distanciated, mediated visual action taking place on the camera monitor screens; and the disembodied, anonymous verbal action over the communicational radio networks (Smith, 2008b). Whilst being an extremely rich and complex environment for an

\footnotetext{
3 Interestingly, as in the current literature on CCTV, those on the street seem only capable of having information extracted from them.

4 To protect the anonymity of the places researched, any names, locations or identities used in this paper are entirely fictitious.

5 An interesting methodological issue arises here concerning the close relationship between surveillance sites and power. To an outsider, the former are 'closed settings' often utilising, perhaps ironically, the Data Protection Act 1998 to prevent their operational dynamics, practices and actions from being scrutinised and made publicly transparent (Smith, 2008b). Such places, it would appear, have control over both access and information.
} 
ethnographer, it took some time to satisfactorily settle in and get to grips with the multiple layers of reality underpinning CCTV monitoring - particularly the long periods of sustained inactivity juxtaposed with the unpredictable and sporadic intervals of intense action (Malinowski, 1922). Moreover, the sheer volume of visual, aural, sensory, semiotic and symbolic information circulating in such places makes this a particularly difficult meaning world to realistically capture, interpret and understand.

Understandable operator wariness in many of the sites researched concerning what I was actually doing in 'their' closed domain, coupled with the often rapid pace of activity occurring, meant that observations were recorded in situ in the form of scribbled notes and quotes, which were then typed up more fully at the first available opportunity. ${ }^{6}$ This initially took the form of prolonged narratives detailing exactly what had happened in each shift, the line of focus gradually shifting to the refined grounded theoretical conceptual categories created. None of the observations or interpretations drawn upon in the following section have been 'checked' for accuracy or validated by either operator or gatekeeper, as it was felt that such a course of action would only serve to reaffirm my identity to them as 'outside' researcher/investigator rather than passive, empathetic background observer. Indeed it was the aim of this researcher from the outset to limit unnecessary disturbance of the settings' socially constructed nature and interaction order. From such a position, and in utilising this particular type of anthropological research method and design, it was felt to be more scientifically accurate to collect and record data in context in as natural and free flowing a format as possible, rather than attempt to 'check' or glean similar information in a 'staged' or inauthentic setting when memory and self have both had time to reflect upon what was said and done, and the minute to minute pressures and workplace cultural practices and rituals are absent (Malinowski, 1922). Moreover, adopting such a direct and unnatural approach might have alienated, angered or affected the operators in some way, placing them on the defensive and thus jeopardising friendships, my continued acceptance in the field and future understandings of their role.

The issues raised in the following discussion resulted from the type of institutional ethnography adopted, and a grounded theoretical approach to data analysis and accumulation (Glaser and Strauss, 1967). The themes 'strategies of control', 'phenomenology' and 'tactics' emerged purely from prolonged time spent in the field as opposed to being formulated by any predefined hypothesis or deductively framed research question. On the contrary, over a period of time, it became apparent from listening to, and speaking with, the operators, while closely observing their interactions with the cameras and those on the screens, that they felt deeply ambivalent about their job role and participated in extensive phenomenological practices. It was also clear that control was negotiated by watchers and watched alike. Once the main themes were consciously identified, each was broken down into related analytical categories. These were: 'management', 'strategies', 'structure', 'physical and symbolic interaction', 'personalisation', 'character construction', 'virtual intimacy', 'story telling', 'Celebnotoriety and Stars of CCTV', 'escapism' and 'reappropriation'. Any statements,

${ }^{6}$ Clearly this method of recording has, due to natural memory erosion, some implications for the authenticity, accuracy and validity of the research findings presented, a limitation openly acknowledged by the author (Fielding, 2001). 
actions and events which related to such concepts were marked, colour coded and, where possible, further pursued in subsequent observations and qualitative interviews. Crucially, data was gleaned and is interpreted in an ethnomethodological sense through the use of members' categories, collective representations and self reporting - i.e. respondents' own subjective experience expressed through their interaction, narratives and body language (Garfinkel, 1967). The accounts presented in this paper are either reflexive extracts taken from the field notes or dialogues from the operators themselves. ${ }^{7}$

The subsequent section is an attempt to pull together the key ideas from the coded categories created, and present them to the reader as an area of surveillance studies which hitherto has been overlooked.

\section{Findings and Disc ussion - the watched as 'subjects of communication'}

Socialization is not simply a one-way process in which the actor receives information, but is a dynamic process in which the actor shapes and adapts the information to his or her own needs. (Manis and Meltzer, 1978: 6)

This piece of research takes as its starting point the general view put forward by McCahill (2002) that the relationship between surveillance and society is a 'two-way' exchange or interaction. Although fairly abstract, the idea can be adapted and applied as a useful exploratory mechanism to characterise the micro communicative process taking place between both watcher and mediated image, watched and CCTV camera. Strange as it may seem, given their physically removed placement and use of seemingly anonymous, in a Goffmanesque sense, 'unsociable' time-space transcending technology, ${ }^{8}$ those watching the cameras are caught within a complex dynamic of both interaction and socialization. Interactions take place recurrently with the surveillance technologies and the ever changing realities displayed on the monitor screens, a corollary form of socialization emerging from the concomitant meaning and significance the operators attach to such images, and from the course of action decided upon (i.e. whether to ignore the picture, continue watching or alert an external agency).

The following discussion presents evidence to support the contention that the people, objects and realities surveilled are not merely passive 'objects of information' devoid of humanness, and meaningful only in their capacity for instrumental analysis, ordering and control. Rather, and drawing on related Media Studies literature focusing on Reality Television (TV), it is suggested that they also appear as active 'subjects of communication', inadvertently producing meaning, action and enthralling scenarios in ever changing forms, often involved (sometimes unknowingly, sometimes reluctantly) in instances of interaction with both the actual CCTV cameras (directly) and their operators (indirectly) (Hill, 2005; Biressi and Nunn, 2005). In this way, CCTV technology functions as a social medium, facilitating social relations.

\footnotetext{
7 For reader clarity, field note extracts will appear in italics, quotes from the operators, in regular font style.

8 The ‘disembodied eye in the sky’ phrase springs to mind!
} 
So as to make these points more concretely and to highlight the differing forms of twoway interaction taking place, I have organised the following discussion around De Certeau's strategies and tactics framework. This enables a consideration of both the contextual 'culture of control' both watcher and watched find themselves within (strategies), and the unintended consequences resulting from the two interacting with and making sense of the situations and environments around them (work and street tactics). The latter process includes instances of direct physical and symbolic interaction occurring between watchers and watched; the operators humanizing and personalising the images, projecting meaning onto and from the machine through phenomenological hermeneutics; and some watched groups employing street tactics equating to evasion and reappropriation. Such unintended consequences are located deep within ontologies of control, and surveillance technologies in particular. The key point is that humans respond to situations of domination in a range of creatively interesting, dialectically diverse and socially significant ways (Scott, 1985; 1990). The human spirit should not be underestimated by surveillance scholars.

\section{Strategies: CCTV and power}

\section{The Control Culture}

CCTV is inextricably connected to its own (and a wider societal) ontology of control, which in turn is linked to power, governance and risk management (Foucault, 1977; Deleuze, 1990; Garland, 2001). In public space, the technology’s rapid deployment is tied to strategic spatial management programmes and policies which place the control of people and movement (through visibility and knowledge) at the zenith of the agenda. Many reasons exist for CCTV's fast growth in the urban metropolis, though it is not important to so highlight (see Norris and Armstrong, 1999). Rather, the central point to note is that the installation of CCTV has been a strategy pioneered by powerful ruling groups in a bid to exert some form of control over public space users. Through the glassy lens of the camera and wider surveillance web, people, animals, objects and behaviours can be monitored, interpreted, categorized and, if a risk, subsequently dealt with. Those wishing to use public space in the UK have now little choice other than to consent to the dominance and watchful intrusion of a camera as they go about their daily business. Yet it is not an even gaze which is being cast. As indicated previously, those already lacking the necessary financial, social and cultural capital find themselves suffering higher levels of control and social marginalisation than their upwardly mobile consumer counterparts. ${ }^{9}$

\footnotetext{
${ }^{9}$ In line with previous research, I also found those excessively 'watched' to be: groups of youths; young working class men and women (especially those with children and prams); street beggars and the homeless; prostitutes; those wearing identity concealing clothing e.g. hoodies and baseball caps; previously 'known' individuals such as convicted shoplifters and drug addicts. At night, public space operators tended to focus on 'places' as opposed to people, with surveillance more reactive as opposed to proactive. Attention during these times was predominantly paid to radio messages between pub and club door staff (if there was such a scheme in operation) and to notorious 'hotspots' associated with disorder - e.g. taxi ranks, cash machines, fast food outlets, entrances to pubs, bars and clubs and places of prior historical significance. Known prostitutes and males in large groups, especially those who had previously been ejected from bars and whose details had been relayed over the radio link, were the main evening targets. Hence the above are what I will refer to from now on as the 'watched'. That said, the various ethnographic 'watcher/watched' examples, which appear later in the paper, do not exclusively involve the 'usual suspects' mentioned above; they also include individuals traditionally perceived as being less 'risky'. Operators, as will become apparent, interact with all and everything.
} 
The continuing growth of public and private policing partnerships, which utilise the latest visual and radio technologies for real time information exchange, mean that urban surveillance webs increasingly extend in reach whilst they tighten existing threads. However, as will become apparent, the watched are by no means powerless to the CCTV gaze; on the contrary, it is they who, for the most part, control its orientation and dictate where it is cast.

Yet the ontology of control connected to CCTV does not start and end with the watched. Perhaps ironically, watchers more generally find themselves increasingly subject to a range of control measures within their respective places of work (Ball, 2001; 2003a; 2003b). Whilst undoubtedly being anonymous and voyeuristic casters of a unilateral gaze, CCTV operators are also intensely exposed to the emotional control of the actual camera images they watch, frequently being overcome by resultant negative feelings of boredom, frustration, stress, guilt, sadness and anxiety (Smith, 2008a). Such workers also find themselves the subjects of more traditional workplace control measures, for example, being: subject to a raft of ambiguous yet legally stringent rules and procedures as to what they can and cannot do; expected to be rationally productive and attain sufficient intelligence gathering 'output targets'; ${ }^{10}$ physically constrained at a control desk in a dark room for long periods of time and for relatively low financial reward. Operators also have the images and radio messages they watch and relay not only recorded and stored, but monitored and often challenged by superiors and others within the web. To an extent, CCTV operators even have the apparent freedom of their gaze controlled by the watched who, through behaviour and social action on the street, effectively dictate where cameras are to be positioned. In addition, CCTV staff generally occupy a position at the bottom of the urban control hierarchy, having no directional power over other actors and agents located within the wider surveillant assemblage e.g. the police, security personnel, pub and club door staff etc.

Thus, CCTV at all levels is connected to an ontology of control made up of many diverse and conflicting forms and strategies. Such measures are interpreted, negotiated and acted upon in many different ways by watchers and watched alike, leading to the emergence of a range of unintended consequences. An empirical consideration of these forms the remainder of this paper.

\section{Unintended Consequences: CCTV as a Social Medium}

\section{Interaction between watchers and watched}

CCTV as a social medium, and the role of watched as subjects of communication, can clearly be seen in the way watchers and watched interact with one another through both camera and screen. Such interaction can take many forms, including operators physically moving cameras up and down with the joy pad in a nodding movement, so as to send out a communication signal of 'we're watching you' or a sarcastic 'hello', and the watched displaying a range of camera-induced responses and behaviours. The following field note extract captures this:

\footnotetext{
10 That is, fill up a logbook with all the incidents of interest which occurred on the shift along with the names, clothing, whereabouts and associates of the known individuals spotted.
} 
Operator 1 watches a male who is sitting speaking to a scruffily dressed female on the steps outside a local authority homeless centre. The man is clearly agitated and appears unable to sit still for any length of time. He seems to acknowledge that the camera is watching him as he initially puts a thumb up to the camera, before making an 'o' shape with his thumb and forefinger (i.e. presumably meaning OK). The operator proceeds to move the camera up and down as if nodding at the male, who then sticks his middle finger up: 'Charming', says Operator 1 , ' $F^{* *} k$ off to you too mate.' The man continues to 'mouth off' and wave his fist at the camera for a further few moments before sitting down, head in hands, on the steps again.

Now that some CCTV systems have audio links, the operators can actually 'speak' in real time to the watched:

Operator 17 notices two young males kicking a football to each other along a station platform. He presses the button enabling him to address the two: 'Stop kicking that football about!' The boys, shocked at the disembodied voice addressing them, pick up the football before sticking two fingers up at the camera fixed on them.

A number of school children are capering beside the platform edge, leading an operator to announce over the tannoy: 'Please get back from the line, or we will call British Transport Police.' The children quickly step back, and order is restored.

Some of the interaction taking place between watchers and watched is more symbolic and personal in nature, involving two-way gesticulations which can range from smiles, waves and nods to a range of impolite hand gestures and an array of comments:

... By this time the observed male has noticed the camera is focussed upon him, and gesticulates angrily towards it. The operator watching the male, responds by sticking his two fingers up at the screen and proclaiming: 'Same to you mate'.

I notice one of the operators focussing a camera on three scruffily dressed individuals (or 'undesirables') standing in an alcove. Two are male, one is female. All three appear aware that the CCTV camera is monitoring them, with the female in particular being quite attentive to this fact. One of the males sarcastically waves at the camera prompting the operator to return the gesture.

Operator 2 follows a 'known' individual as he makes his way along TT Road. The male has not been seen for a while, and the operators in the room struggle to remember his full name. Interestingly, the man, who clearly is aware of the cameras following him, suddenly stops and begins 
pouring his can of lager down a street drain. ${ }^{11}$ He turns to the camera, smiles derisively and gesticulates with a 'thumb up' gesture. The operators wave at the monitor screen and laugh sarcastically: 'Oh what a good boy! Can't say I've ever seen him do that before, he usually doesn't waste his drink', says one. Shortly after, the male deposits his now empty can in a nearby council bin. Again, the operator laughs and mockingly claps the man for being such a 'good citizen'.

Although interacting indirectly at a distance, the operator was evidently enjoying keeping a watchful eye over the man and seeing him respond to her incessant surveillance. At the same time, the male clearly knew he was being scrutinised and modified his behaviour accordingly. Interesting issues arise here. The official and institutional role of CCTV operator is as a detached observer, emotionally uninvolved and instrumental in their judgements of what they watch. Yet the informal role of operator in reality is one of an 'absent presence' - i.e. physically removed from the action, but symbolically and personally present within it. Whilst protected from the physical reactions of the watched and thus empowered, operators are simultaneously unable to physically impose any authority onto a given situation. An ambiguous position, as can be imagined. Yet it is apparent in the empirical examples provided that the watchers subconsciously use cameras as vicarious agents in order to extend and thrust themselves into the action, albeit through mediated means. This inevitably leads many to become both personally involved in, and subjectively affected by, the action and interaction in which they indirectly participate. In similar vein to Reality TV contestants in the Big Brother game show diary room, the watched also seem to treat the electronic eyes in the sky as more than just lifeless technological objects. Indeed, their actions and behaviours are indicative of individuals reacting to the symbolic presence of an unknown human observer, as clearly demonstrated in the case of the previous field note extract. In other words, there is enough empirical evidence to suggest the conduct of watchers and watched incorporates a humanization of technology process, both parties personalising and actively attributing social meaning to that which is seemingly inanimate. Through their interactions with the cameras, the two appear to be trying to recreate the norms of routine face to face interaction, attempting, as it were, to normalise an unhuman and distanciated form of social control (Goffman, 1959; 1967; 1971; 1974). In effect, their actions are symptomatic of individuals seeking to break down the technological barriers they are positioned behind.

\section{Unintended Consequences: Work Tactics}

Humanizing Technology - the watchers and hermeneutics

Watching hundreds of television screens intently for hours on end in a bid to spot disorder and 'suspicious' individuals is no easy undertaking. Despite initially appearing an interesting and glamorous pursuit for many (for its obvious 'people watching' voyeuristic opportunities), such viewing quickly becomes a monotonous, repetitive and onerous task. Whilst each shift is unpredictable regarding what may happen on the cameras, for the most part, everyday life in the public arena follows a generally routinized, orderly

\footnotetext{
11 It is an offence to drink alcohol outwith licensed premises in the city centre, with a fixed on-the-spot fine of $£ 40$ for those breaking this law.
} 
trajectory. Moreover, the hundreds of televisual screens which in turn produce millions of disjointed, time-space compressed images on a daily basis, leave the operators continually having to interpret, sort and organise what is seen, whilst cope with the pressures of missing an incident and the advent of information overload and corollary operational dysfunction. The threats of frustration, stress and alienation are never far away from this particular workplace culture (Smith, 2004).

It became quite apparent from the observations that a crucial way in which CCTV operators interact, make sense of and bring meaning to the diverse and ever changing array of televisual imagery in front of them and the ergonomically imprisoning confines of the 'room of control', is through a form of hermeneutical phenomenology (Gadamer, 1979). This process, paralleling the actions of television and cinematic audiences (Hill, 2005), involves the operators subjectively and ethnomethodologically 'reading intentions' and interpreting what they see in conjunction with their own personal biographies and non-work narratives, imaginatively creating identities and biographies for those watched and providing the unfolding action with a range of inventive commentaries. Crucially, these depictions are often shared amongst the other operators in the form of workplace banter. Such informal tactics, utilised mainly for understanding, ordering and general amusement, along with the cathartic release of conflicting emotions, are, I would argue, one unintended outcome of, and response to, a system which has, at its core, an ontology of rational control and, on its surface, strategies of management designed to induce conformity in both watchers and watched (Brubaker, 1984). Yet, whilst an unintended property of this particular control system, it does not follow that the subversion by operators of their formal role necessarily undermines the extension of CCTV's rational power. On the contrary, operators generally employ such tactics to counter information overload and provide light relief from what is an emotionally exhaustive job. To this end, the practices utilised actually create an intimate connection with what is being watched, facilitating the formation of a shared workplace culture (thus reality) and worker productivity. Thus the operators' work tactics appear to perform at times a dual function of both social and systemic integration (Lockwood, 1964).

\section{Character construction}

Much like the protagonist 'Jeffries' in Alfred Hitchcock's voyeuristic classic Rear Window (1954), one of the fundamental hermeneutical practices operators regularly perform is to attribute and provide those they watch with a plethora of pseudo, often crude, identities:

The time is around 11:30pm, and two operators are watching and laughing about a woman who it has been suggested, 'looks like ET dressed up'. The woman, no more than five feet in height and in her early fifties, appears to have had too much to drink and is currently walking along the street unaccompanied ... A short time after, one of the operators comes back into the room asking where and how ' $E T$ ' is.

'What I do [when bored] is make up stories for people I watch on the cameras and call them names.'(Operator 1)

A CCTV operator is asked by the police control centre to have a look at 
the Bus Station, as staff there have reported a drunken male being threatening and abusive. Operator 11 takes a look at the camera covering the station, and on seeing nothing out of the ordinary, focuses on one particular individual and asks myself and the other operators whether we think he, 'looks like Jasper Carrot?'

Most of these accounts are swapped amongst shift members and other shifts, thus helping to formulate a shared workplace culture; even to the extent that some of the watched have identities attributed to them which have become fetishised in the room of control:

[Talking about a known individual] ... 'At the start we didn't know what his real name was so we called him 'Disco Dan' and it has just stuck and now the whole team [all the operators] know him as that ... as he used to always hang about outside the discos.'(Operator 19)

Such characterisations and forms of labelling closely parallel the types of discourses television audiences construct for the programmes they view and the 'characters' whose lives they so intimately invade, particularly those consuming Soap Opera and Reality TV broadcasts such as Big Brother, Shipwrecked, Survivor and Celebrity Love Island (Denzin, 1995; Hill, 2005; Biressi and Nunn, 2005). All of the operators have grown up in a culture saturated with global televisual and cinematic imagery, fuelled in recent years by cable and satellite television and a rapid growth in mediated ocular Internet entertainment, perhaps most starkly seen in the popularity of websites such as My Space and You Tube, where budding amateur musicians and directors can upload their homemade videos for world wide exposure and consumption. Thus it is perhaps unsurprising that operators locate anonymous CCTV subjects within such wider media frameworks, subconsciously using references, knowledge and comparisons taken from the televisual-driven popular cultural they inhabit for meaning, sometimes drawing upon and projecting such discourses and experience in a bid to make sense of what they watch:

'I just treat the screens in here like I'm watching television. Helps you cope with what you see. It's funny 'cos a lot of the people we watch are like characters from TV, so it does become a bit like that. And gradually you begin to learn who they are and which places they hang out.' (Operator 5)

'I used to watch a lot of telly but I don't bother watching 'real' TV anymore as this is enough for me. The last thing I want to do when I finish a ten hour shift in here is put on the TV - you see everything in here anyway.' (Operator 9)

Other times operators adopt the role of 'audience spectator' for purely entertainment purposes:

Operator 6's attention is drawn to two cyclists hurtling along. Suddenly, as the two turn left, one of the cyclists decides it is a good idea to cycle along the ledge of a forty foot high bridge! Despite being an extremely dangerous thing to do, the three of us sit amazed watching the male cycle 
across to the other end of the bridge, before jumping down and back onto the road ... 'It's better than SKY TV's extreme sports programmes in here.' (Operator 11)

Perhaps thrills from the 'Real McCoy' of reality shows are now more alluring to the operators than those offered by 'normal' TV? What is apparent is that the distinction operators make between television, CCTV and reality is perhaps rather ambivalent and an area requiring further exploration.

\section{Familiarity, personalisation and the creation of 'Celebnotoriety'}

All the world's a stage, and all the men and women merely players; They have their exits and their entrances [in and out of the camera's gaze]...

(William Shakespeare, As You Like It, Act II, Scene 7)

Most of the interaction which the operators have with the watched takes place within a context of familiarity and within a relationship that is pre-existing (albeit unilateral), having been assembled over time. The job of CCTV operator involves monitoring thousands of anonymous bodies, places and objects located across time and space. Yet through the lens of the camera, incidents occur, relationships become established and special 'characters' emerge. Indeed, through the very process of negative, socially constructed sorting and targeting comes familiarity, personalisation, intimacy and often a certain fondness. For the operators, the watched are not victims, as much as the Stars of CCTV. Indeed, without their corporeal presence, work for the operators would largely become routinized, mundane and meaningless. They bring colour to the greyness of everyday life. They bring interest and entertainment to what essentially is an alienating job (Smith, 2004). And so the creation of Celebnotoriety takes place. Conceptualised in this light, CCTV monitoring is akin to watching a citywide soap opera. With streets, malls, campuses, shops, stadiums and stations as the backdrop, CCTV operators as the audience and screenwriters, a range of shoplifters, alcoholics, prostitutes, beggars, drug dealers and abusers as the principal cast - the general populous playing minor, cameo roles - meaningful relationships are formed between watchers and watched, the operators never knowing what tomorrow's story will be:

'Where's 'Benny' been hiding? Haven't seen him for a while. Kinda miss not having him around, trying to get one over us. We used to play hide and seek games with him around the graveyard as he tried to either dump or pick up stolen items.'(Operator 3)

'Yeah he’s [i.e. Benny] a real character, we always get a laugh with him.' (Operator 6)

The time is now 11:21am and Operator 12 is focussing on a known person as he makes his way along Central Square and then onto GG Lane. She asks Operator 11 to: 'Check out the state of 'Derek'! He's clean, and he's got matching shoes on; can you believe it? And he's had a haircut. He must have been in care somewhere.' Operator 11 retorts: 'I can't believe that's him. That's the first time I've seen him looking like that. Mind you, I 
haven't seen him in a while. Just wait a few days though, bet you he will be up to his old tricks again. One missing shoe and a bottle of voddie!'

The Stars of CCTV have become celebrities in the spaces they occupy and, despite presumably the attention being for the most part unwanted (although it may in fact build 'peer status' for some individuals, such as 'Neil' (see later)), it is virtually impossible for them to venture anywhere without attracting almost paparazzi-style interest:

Operator 10 has picked out two prolific shoplifters, a male and female in their early twenties, scruffily dressed pushing a young child in a pram. I am told that these two are the area's worst family of shoplifting offenders. There's a whole family of them and they're all into crime. These two are the worst for shoplifting, they often hide stolen stuff in the pram.' The operator immediately warns all Shopwatch radio users that the two are crossing AA Street and are currently heading in the direction of Virgin Megastores and the local shopping centre. She gives a detailed description of the two, stating that they have 'got the pram out today.' A minute or so after she has relayed the message, a security guard is heard stating that the two are crossing his shop entrance. This passing of information by CCTV operators and security guards from a plethora of different stores, regarding the whereabouts and attire of the two, continues for some time. It becomes almost comical as the family make their way up and down $A A$ Street, on either side of the road, attracting incessant audio commentary and with cameras following their every move.

Although empowered through the physical anonymity such distanced mediation affords, the watchers, much like the Stasi agent, Gerd Wiesler, in the film The Lives of Others (2007), can develop psychologically ambiguous, almost intimate relationships with the Stars of CCTV leading to the regular occurrence of surreal episodes:

'It's a weird feeling [passing known individuals when shopping]. To think we know so much about them, but they don't even know who we are; it's strange. I mean some of them we have a right laugh with when we're behind the cameras, you almost feel like smiling at them when you pass them on the street!'(Operator 6)

'I've managed to get a guy prosecuted who lives near me; he frequently speaks to me when I bump into him in my local shop, having no idea who I am, or that I’ve had him lifted!'(Operator 4)

The qualities which create a likeable celebrity character vary depending on the age, gender, class and ethnicity of the operator, but common characteristics are an individual who: is a screen regular (i.e. in public space a lot); has defining features (e.g. distinguishable attributes or attractive looks); acts up in front of the cameras (i.e. by smiling or gesticulating regularly towards them); has an almost mythical reputation or 'interesting' personal life (e.g. a prolific offender or a person regularly courting other Stars which, as in a Soap Opera, leads to tensions around the town and the operators playing 'memory games' with one another so as to determine the current partner); amuses 
the operators (e.g. through their behaviour or by trying to outsmart them). ${ }^{12}$ Such relationships can develop to encompass even a special kind of fondness for the 'urbancelebs':

Flicking through the cameras, Operator 1 recognises an individual notorious for shoplifting and other offences, and tells me affectionately that she likes this particular male because, 'He's harmless and he commits so many shoplifting offences every day, that he often doesn't know what he's wanted for! So we follow him on the cameras until he sees them move [the Stars are all generally camera aware] and he gets paranoid thinking that the police are after him and tries to hide... I've seen him run all the way up GG Street in tears ... It amuses us!'

I am told about the tragic death of an individual who died from a drugs overdose. Operator 19 goes on to tell me the circumstances around her death and the type of person that she was, as all the operators 'knew' her well: 'She was pretty well known round the town. A nice girl ... just fell into the wrong crowd which is a typical story ... I mean I know it sounds strange, but you form a kind of relationship with some of the people you watch, some of them are alright. And it's sad to think that you won't see them going about anymore, but that's life isn't it?

A call from Shopwatch radio link that a known shoplifter is moving in the direction of GG Street, has Operator 10 quickly picking out and zooming in on the aforementioned. The male looks up at the camera as he walks toward the GG Street pedestrian crossing before sharply looking down as if to avoid the camera's gaze. The operator proclaims, 'Hello 'Mark' to the screen as if the man can hear her. 'What have you been stealing today then Sunshine? ... He used to be quite cute, but he's got all thin and gaunt-looking now 'cos of all the drugs.'

Operator 8 has located and is following a known prostitute/drug addict who is accompanied by a male: "Yeah that's 'Suzanne'. She used to be a very pretty girl but she ballooned right up when she was on the drugs and drink.'

This fondness can even seemingly transform urban surveillance into a game of playful cat and mouse:

'If they see us looking at them [through the cameras], they'll often wave back at us or gesticulate ... It's all in good humour. Sometimes when they're pissed off that we've spotted them, we'll deliberately follow them from camera to camera until they see the funny side and cheer up! Passes the time, you know.'(Operator 3)

${ }^{12}$ Those who are violent are generally cast as 'rogue Stars', 'bad guys' or 'outlaws'. 
He's ['Neil'] one of those that loves to think he's important and often plays hide and seeks games with us on the cameras. He really gets off on thinking that we're following all the time on the cameras, and that we're interested in him; suppose it makes him feel important. I think he likes boasting to his mates that he's made a name for himself among the police and is 'well known' and 'respected' in the city [by criminals] when in actual fact, he's just a bloody pest, who starts crying every time he's picked up.'(Operator 15)

Their access to institutionally held databases and informal networks of information exchange, means that CCTV operators often supplement their visual role with knowledge of the most intimate details of their subjects lives - for example, they are aware of current relationships, extended families, criminal records, drug intake etc. and where the watched generally frequent and live. Some take this to relatively extreme levels:

'Yeah I've learnt most of their [the Stars of CCTV] dates of birth off by heart [through having to habitually check to see if they are 'wanted' on the Police National Computer (PNC)]. Pretty sad isn't it?! It’s funny, I know more about the criminals than I do about some of my family.'(Operator 5)

Such personalisation and feeling toward, even fascination with, those watched, can have both positive and negative impacts on decision making processes, significantly altering the course of justice administered, as the following dialogues demonstrate:

A doorman at Jonah's bar alerts two operators to a male 'begging aggressively' and being a 'general irritant' outside their premises. He asks for a police unit to get rid of him. A description of the man is given and Operator 12 quickly spots him on camera: 'Oh that's 'Johnny', he's not a problem. We often watch him rake through the bins and try and sell stuff to taxi drivers and other punters.' The same operator watches the man approach numerous people apparently asking for money, and then moving on without fuss when they either ignore him or decline his advances: 'I'm not calling the control room, as he's not causing anyone any harm. I feel kinda sorry for him.'

The time is 20:30pm and Operator 4 is on general surveillance duty (GSD) when she spots someone she thinks she knows getting out of a car: 'I'm sure that's 'Scott'. She asks Operator 9 to check the PNC to see whether there is an arrest warrant out for the individual before stating: 'I really hope he is wanted for something ... I really hate him, he's a nasty piece of work. Operator 9 says jokingly that she thinks Operator 4 has a 'personal' vendetta against the man: 'She's always after this guy every time he steps foot in town, she's absolutely possessed.' Operator 4 responds, 'Nah, it's just he's better off locked up - he's really into his drugs and is incredibly aggressive ... It's where a scumbag like him belongs.' Operator 9 confirms that the male is wanted by the police.

Interestingly, one operator from a shopping centre studied feels great sympathy for the 
predicament of those watched. After telling me about a personal experience he himself had undergone, relating to a loved one's own battle with drug addiction, he said:

'I treat them [the Stars of CCTV] with respect, as it is easy to fall into a downward spiral. They are just like you and me. Unfortunately they’ve just fallen into the wrong crowd. The more human we are with them, the more chance they might kick the habit and get back on the straight and narrow ... I have a good laugh with some of them, and even gave one money the other week when I was on patrol on the mall [the operators cover security guards' breaks] so that they could get a drink when they were on a downer. If you treat them with respect, they generally act the same way back.' (Operator 20)

Much of the observational literature on CCTV seems almost to neglect the fact that operators can exercise in their gaze care, empathy and compassion as well as prejudice and intolerance.

Personalising the screens and the protective gaze

CCTV monitoring is not all about control and domination. Due to the virtual intimacy operators experience with the action and people observed, some develop an almost extended obligation of care for those watched. In contrast to Norris and Armstrong's (1999) research, which found the protectional gaze - i.e. concern for a person's welfare or safety - exercised by operators in only two per cent of all Targeted Surveillances, my research established it as common practice in the public space monitoring facilities. Lyon's (1994; 2001) theoretical argument regarding surveillance technologies as being operationally 'Janus faced', that is, enabling and constraining and characterised by care and control, can clearly be seen in camera practice at the micro level:

Operator 5 flicks through the cameras and notices three very small children, around four to seven years old, playing games in a doorway. The time is 9:42pm. She zooms the camera in on the youngsters and continues to monitor the children. A short time later, a teenage girl, a male in his twenties and an older woman appear on camera, and the three children leave the steps with the adult trio. The older woman (who is previously 'known' to the operators) is identified by the operator as being the children's mother and she continues to watch them as they make their way along the street.

'Last week I had to find an old biddy her Wallace Arnold coach, as she'd got lost while shopping! I've done that a few times for people.' (Operator 8)

The time is 04:30am and Operator 2 is flicking through the cameras when her attention is drawn to a single, elderly person walking west along CC Street. She zooms the camera in on the individual, clearly recognising the woman. She informs me: '[the woman] is a 'known' old dear who is currently registered as a missing person and whose safety has been a source of concern to the police over the past few days.' She alerts the 
control centre and a police unit is despatched to return the woman to the safety of her care home.

Operators can be seen to construct imaginary stories that legitimate an observed person's presence in time and space, effectively presenting them as a subject requiring care:

The time is 11:20pm and I notice Operator 11 watching an elderly woman on her own, loosely carrying her handbag and a bag of shopping, shuffling along HH Street. I comment on the fact that it is quite late for a pensioner to be walking the city centre's streets on a Friday night: 'She has probably been at the Bingo or visiting a friend. She's very smartly dressed. I just feel I've got to follow them [i.e. the elderly] to make sure they are alright.'

In the biographies they attach to those they watch, some even associate those on camera with individuals from their own personal lives:

A doorman asks CCTV to keep an eye on a male who is 'far too drunk for his own good'. The male is monitored closely along DD Lane, regularly colliding with people as he stumbles. The operator is afraid the young man, despite not being in any way aggressive, might bump into the 'wrong person' and be subjected to an assault. He is watched for the next five minutes until the operators' attention is diverted: 'Maybe sometimes I'm too motherly for this job, but I can't help thinking that that could be my son.' (Operator 11)

Gender is clearly a significant factor behind the initiation of a caring CCTV gaze, with four of the examples being instigated by female operators, the majority of whom were mothers. Perhaps this implies that the 'disembodied eye' carries a more maternal projection if activated by an older female operator? An area certainly worthy of further investigation.

Creating and telling stories

As indicated, operators do more than just create identities for those they watch. They also subvert their institutional role by constructing and recounting stories about the world they spend their lives observing (Goffman, 1961). These narratives help pass the time, attach value and significance to abstract individuals and events, and create an outlet away from the monotonous and often traumatic job of watching continuously a series of televisual monitors and real-time crimes taking place:

Whilst looking at the pedestrians zone at the rear of a major shopping centre, an operator watches two boys around eight or nine years old for a number of minutes, one of whom is doing gymnastic cartwheels on the street. His mother appears to be in one of the public telephone boxes making a call: 'He's pretty good at the first two or three, although by about the seventh one in a row his shape is struggling a bit. It's more horizontal as opposed to vertical. Not sure if he'd win a gold medal for that one! Ha-ha!' 
A young male, no taller than five foot seven inches, apparently arguing with the bouncers at a nightclub entrance, attracts Operator 4's attention. It would appear that he has been ejected from the club and would like to re-enter. The young male squares up to the doorman, but decides to step a few paces backward when a second doorman joins his colleague. Half jokingly, and towards the screen, the operator advises: 'Just walk away ... just get in a taxi mate and head home. You're never going to win this fight ... He'd never do that if he was sober.' He walks towards the car park directly adjacent to the club and sits on the wall whilst making a call on his mobile phone. 'What he needs is for his girlfriend to come out and for them both just to leave and get a taxi home.'

'I did get some entertainment last night. I saw a group of seagulls in the middle of the road feeding on some leftover food. This taxi came along and slowed right down but the birds just weren't paying any attention, so he just speeded up and went right over one of them. It was really funny. Made my night!’ (Operator 5)

The time is 1:13pm. Operator 6 is monitoring the red light area and notices a known prostitute: 'Blimey she's out on the go early!' A male jogger suddenly stops beside the woman, chats for a short time and then enters into a nearby flat with her. Both operators burst into laughter, one saying: 'That's pretty sly, [pretending to be the jogger speaking to his wife] 'I'm just out for a run love, won't be long', and the boy's off with some prostitute. I tell you what, when my husband goes out for runs he better not be coming down here!" General laughter erupts and Operator 7 makes the observation that the female operators, 'shouldn't just jump to conclusions' and that 'perhaps the chap lives there and she was just letting him in?'

Such phenomenological storytelling parallels the conduct of television audiences, who also are in the process of making sense of and ordering the images viewed (Gauntlett and Hill, 1999). Moreover as Gray (1992: 214) argues, 'a very important part of the pleasure of television serials is to gossip about them the following day' and operators delight in relaying to one another not only what they have seen on camera, but also what has been happening in their personal lives and favourite TV programmes. It helps make the job meaningful to the operators and establishes a shared sense of reality within the informal workplace culture. Perhaps more importantly, the accounts enable the operators to temporarily 'escape' from the negative mediated realities they are caught within and, as such, should be seen as unofficial coping strategies (Smith, 2008a; Cohen and Taylor, 1992). Overall, CCTV monitoring must be seen as a distinctly social activity, and one which incorporates entertainment and particularly social learning.

\section{Learning through watching}

The operators learn, often through 'secondary adjustment' (i.e. the subversion of an institutional role for alternative purposes - in this case through use of the cameras ((Goffman, 1961)), a great deal from watching people at work and at leisure, picking up 
on the latest urban fashions, also accumulating in the process a tacit, yet comprehensive, knowledge of a wide range of social practices and phenomena:

I notice Operator 1 focussing the camera on a woman's pink shoes as she crosses GG Street: 'Oh I like them, they must be very fashionable, I've seen lots of girls wearing them.' A short time later, she zooms the camera to check out a woman's bag as she chats to a friend on PP Lane and tells me that, 'I've got that bag. Cost $£ 10$ in New Look.'

'When I go out [at night in town] I never go to the three main taxi ranks, as they're always slower moving than the FF Street one.' (Operator 6).

Prolonged visual exposure and interactive and interpretative work, also effectively transforms operators into expert situational risk assessors, behavioural analysts and body language 'specialists'. The following miscellaneous extracts are typical examples of the 'learned experience' garnered from watching everyday life unfolding and the development of what may be seen as operator created 'interpretive rules':

We get on to talking about whether operators can intuitively predict if there is likely to be trouble or not on certain nights in town: 'Yeah I think you can. You just sense an atmosphere [in town] even from within here. A lot of it has to do with the weather. If it's raining it means that people are more likely to want to get home quicker at the end of the night, so you don't get as many queues and people hanging around outside [food] takeaways when the clubs shut. Usually means there's less trouble [i.e. violence and disorder].' (Operator 3)

'Because the scummers are all creatures of habit, they always go to the same places and areas like the telephone boxes or to the chemist to get their Methadone. There are certain places where they just seem to congregate. You just develop an awareness of people.' (Operator 6)

Operator 8 is radioed by door staff to monitor two men apparently squaring up. Although the potential for violence would appear great to the untrained eye, the operator refrains from alerting the control centre, instead monitoring the behavioural dynamics of the situation closely herself: 'A lot of these types of incidents don't actually come to anything', she informs me ... She continues to observe the incident attentively for around five minutes until the man is eventually pulled away by his companions ... Clearly this is an example of how the operator's behavioural intuition and expertise, leading to the correct diagnosis of the situation was proved correct.

'Those who are pumped up, confrontational, moving aggressively or clearly agitated about something, are usually the fighters. It's hard to explain, you just know.' (Operator 12)

Learning from watching is not always a positive experience; previous incidents and 
experiences often leaving operators with a profound fear of urban space and leading to corollary behavioural adaptation:

'I don't really go out at night any more in case I bump into the wrong person in a bar or taxi queue ... 'cos I've seen what happens to unlucky people.' (Operator 3)

'Camera 46 is the 'methadone camera' ... that's the one we watch around 10:00am when all the druggies go and get their daily methadone. I would never go to that pharmacist.' (Operator 9)

The influence of the operators' non-work lives on the type of gaze projected is significant, some adopting secondary adjustment of the cameras for 'pragmatic learning' purposes:

As Operator 2 is pregnant, she has been recently zooming in and making mental notes on each pram she comes across: 'Not sure I like that one, looks a bit like a shopping trolley.'

A tendency exists within surveillance studies research to equate the practice of surveillance with a singular and standardised gaze characterised by discipline and control. This is a naïve assumption. The micro examples provided above bring out the relativized and pluralistic nature of the gaze(s) emitted, and show how such watching is underpinned by a range of formal and informal situational factors, being initiated for a variety of contrasting reasons. Indeed, I would strongly urge scholars interested in understanding and theorising the differing type(s) of gaze(s) surveillance workers cast, to take account not only of institutional context, official worker role and organizational goals, but also the personal goals, biographies, habitus and non-work subjectivities of the workers themselves. Following such advice will provide the field with enhanced awareness and better understanding of the diversity of surveillance gazes in operation.

\section{Unintended Consequences: Street Tactics}

We are concerned with battles or games between the strong and the weak, and with the "actions" which remain possible for the latter. (De Certeau, 1984: 34)

Just as the operators have developed tactics to cope with the physical and emotional imprisonment they experience and the controlling glare of the televisual screens, the watched, it would appear, have also created a range of measures to counter and negate the predominantly controlling (strategical) gaze of the cameras. One may describe them as secondary 'experts' of the system (the operators being the primary experts), aware of how the cameras work (i.e. what they can and cannot do), where they are located, where there are 'blind spots' and how to exploit such weaknesses.

\section{Entrepreneurial defiance}

Whilst the current literature largely contends that power lies firmly in the gaze of CCTV controllers, observations within CCTV showed the watched as perhaps slightly more 
resistive and entrepreneurial than are given credit for, regularly 'outwitting' or 'outmanoeuvring' the operators with a number of tactical ploys, sometimes even using the cameras to their own advantage. Indeed, it is the Stars of CCTV who determine where the gaze is cast, in a sense weakening the operators' power to freely watch over space. It must also be remembered that whilst CCTV operators are aided by strategically situated eyes on the ground and time/space transcending radio links, they have often upwards of forty monitors to try and watch simultaneously, calls to answer and a range of institutional goals to fulfil and non-monitoring tasks to achieve (Helton and Fischer, 2003). Further, as already documented, socio-structural and socio-cultural factors, such as organisational conflict and lack of technological skills and know-how, often leave CCTV rooms of control in a state of relative chaos and disarray (McCahill and Norris, 2003; Norris and McCahill, 2006). Moreover, CCTV operators often find their ability to physically respond and impact upon the situations they watch significantly hampered by limited embodied resources, with 'troops' on the ground often in short supply. This leaves the watched, most with only one specific goal to achieve - be that shoplifting, selling drugs or stolen goods, avoiding detection due to being 'wanted', courting male clients for sex, begging or simply 'hanging around' etc. - at times carrying the 'higher ground' advantage in an increasingly tactical game of guerrilla warfare. This is brought out in the following accounts:

\section{'Dirty' tactics}

'Yeah we've got one banned scumbag [beggar] who sets up 'stall' right underneath the camera where we can't see him. It means we've actually got to send a guard over periodically to check if he's there. It's a real pain in the arse. He might be on the street but he certainly isn't stupid.' (Operator 18)

Operator 2 follows two girls suspected of shoplifting on to a bus, before informing me that suspects, 'often get on a bus for one or two stops and then get off just to try and outsmart and throw us [i.e. CCTV] off their scent.'

I am told about a £20,000 robbery that took place the previous evening in the city centre. An electrical store was broken into and the entire shop ransacked. It turns out the police have no CCTV footage to go on, as the 'cunning gits bloody knocked all the surrounding cameras up with a pole so that they were facing the sky while they raided the store.' (Operator 9)

Operator 13 states that it is getting harder to identify all the shoplifters in the city as, 'we get criminals now from outwith the city coming in to do some shoplifting. [Similarly,] those who have been inside [i.e. in prison] for a while ... they can come out looking completely different.'

The watchers frequently partake in cat and mouse, hide and seek-style games with the watched, one Star of CCTV in particular, a habitual shoplifter and drug addict, 'Billy', garnering cult figure status among the local operators, even admiration, for his dirty tactics: ‘He’s some boy’ (Operator 7); 'He just disappears into thin air’ (Operator 11); 'an 
absolute and utter pain in the arse' (Operator 9). Billy is well known to fully exploit public/private space CCTV camera 'blind spots' when stealing items and making his escape. Moreover, it is not uncommon for him to literally 'hide' behind patrolling guards within the local shopping mall so he can slip into shops and malls undetected, thus evading 'capture'. Billy's expert resistive skills enable him to frequently steal and escape with vast quantities of goods on most days of the week. He even chooses an 'optimum' moment to launch his attack, around closing time when the shops are quiet and staff are either tired, tidying or cashing up, effectively leaving him easy pickings. A similar Star is 'Neil':

'He’s a right bugger him. He doesn't really shoplift, but his favourite trick is to block up parking machines with something and then go back later and collect the trapped money with a coat hanger. Took us a while to catch him doing it, but he was stupid enough to target parking machines in the same street! He's got lots of tricks to make easy money, then, as soon as he is picked up, he puts on his act of appearing illiterate, pretending he has learning difficulties and any other disorder that excuses his behaviour. But he's as sharp as they come when it comes to scams.' (Operator 15)

\section{Logistical expertise}

Adding further light artillery to their arsenal, many of those watched have become tactical experts both on camera locations and present positioning. As such, they appear to know all the side streets and 'blind spots' that can make successful negotiation of the CCTV minefield a realistic possibility:

'[The watched] are experts of their trade. Don't underestimate them, for every one that we catch, nine times out of ten they get away with it.' (Operator 18)

Certainly one store security officer held the view that thieves had discovered when the part-time operator was off duty in that he noticed more known 'faces' on the operator's rest days (quoted in Loveday and Gill, 2003: 112)13

'Yeah the criminals are 'streetwise' alright, and they're well aware when we're watching them ... so they try and dodge us by: deliberately not looking up; going along streets out of our view; staying in the shopping centres; or watching the cameras to see where they are pointing to try and tell whether we're watching them or not.' (Operator 10)

The suspect shoplifter is picked out by Operator 13 in around thirty seconds, who then skilfully follows him until he heads down a side street outwith the cameras' gaze. This prompts the operator to curse, 'The buggers are well aware of the cameras' positions and frequently dodge them via the back streets.' I have already twice today watched a 'wanted'

\footnotetext{
13 Clearly in this example offenders were targeting the store when they knew they would be less likely to be monitored.
} 
individual make a successful getaway through the side streets and utilise areas outwith CCTV coverage.

Evidence would suggest, then, that a fundamental skill the watched must learn in order to become fully 'streetwise' is an expert awareness of CCTV, learning where the cameras are positioned and if they are being observed. This is another area which could be usefully explored with detailed qualitative research.

\section{Going undercover}

If all else fails, deceiving the enemy is possible by going 'undercover' in a bid to try and merge into the urban jungle:

Times have changed ... the thieves have adapted to the situations and locations, they come in with suits and ties [now]. (CCTV operator quoted in Helten and Fischer, 2004: 34) ${ }^{14}$

A number of the watched in the research were seen to wear caps, parka jackets, hats and hooded sweatshirts, most likely in a bid to conceal bodily identity. In a distinctly Goffmanesque light, and from week to week, the same celebrities often changed the places and spaces they frequented and the people they were with. Many brought with them to the action new (and anonymous) Co-Stars which frustrated the operators. ${ }^{15}$ They changed their line of attack by choosing different entry points and targets. They swapped various 'props' (e.g. prams, dogs and bags etc.), 'costumes' and even altered their personal appearances by growing or shaving off beards, wearing glasses and changing hairstyles. Moreover, I was told about certain Stars who deliberately used their 'Celebnotoriety' around the town to attract, distract and channel the gaze of the operators, leaving lesser known accomplices to pillage the shops, people and areas now effectively unprotected. I would argue the watched used such ploys in order to both throw agents of control off the trail and negotiate the system. Whilst being low in technical sophistication, the practices could be deceptively effective; for example, celebs (who I now knew) would frequently reappear on camera later in the day (often when a shift had finished), with different individuals and sporting new guises, and be subsequently missed by the wider web (having been 'smoked out' earlier by the occupying surveillance forces). Again, further research is required in order to discover whether the above amount to conscious intentional tactics or, more unlikely, coincidental serendipity. Other, more experienced Stars, or those 'retired' from conventional criminality, appear to be unperturbed about being watched, knowing there is little the operators can do other than simply passively observe them. Perhaps unsurprisingly, these Stars are often the least 'appreciated' by the operators.

\footnotetext{
14 As the quote suggests, perhaps operators are recognising that the use of wider social stereotypes to guide judgements regarding criminal intent are often misplaced. Perhaps in time this will result in the replacement of subjective human operators with computerized algorithms (strategy adaptation) in an attempt to locate an increasingly hidden enemy?

15 Such individuals were then often given pseudo-names and biographies (which sometimes stuck) until genuine names and details were established, either through consultation with other shift operators, security guards or police officers in the wider web. Interestingly, their very presence with the Stars of CCTV, as far as the operators were concerned, meant they were 'up to no good'.
} 


\section{System subversion}

Protecting the truly vulnerable is not the job of a contemporary urban surveillance camera. In building 'safer cities' for corporate growth, the poor, if visible at all, have become irresponsibilized eyesores whose stake in the new fangled neoliberal channels of citizenship and political representation is being eroded. (Coleman, 2004: 306)

Contrary to Coleman's commentary, many street beggars actually choose to sit in direct view of CCTV cameras, those spoken to in passing suggesting that knowing the cameras were watching over them made them 'feel safer' as they tried to earn a living. A similar form of reappropriation is also effectively adopted by numerous prostitutes within urban red light zones, many choosing to court business on well-lit streets in full view of public space, and thus monitored, cameras (where any prospective 'client's' face and car registration plate can effectively be captured), as opposed to soliciting in dark, cameraless back streets where dangers are greater (The Week, 28 January 2006: 13). Both forms of reappropriation equate to conscious tactics on the part of society's vulnerable who, although physically most at risk of danger and socially excluded, actually use the surveillance system as a means of enhancing their physical and ontological security (Giddens, 1984). In other words, the surveillance system provides a sense of order and security for particular groups who conventionally are perceived as threatening both. Whilst few operators construct narratives of care for the Stars of CCTV when watching them, the incessant monitoring and scrutiny of their actions, paradoxically, minimizes the risk of any harm befalling them. Perhaps ironically, the Stars of CCTV are amongst the safest individuals in urban spaces! A fine example of the ambiguous nature of surveillance and yet another unintended, but socially significant, outcome underpinning contemporary CCTV's ontology of control.

\section{Conclusion}

This paper has shed light on a hitherto under-researched and under-theorised area in surveillance studies, the technologically mediated and distanciated interactions and relations occurring between watchers and watched across a CCTV network. Such technologies of control, it has been shown, are social mediums facilitating interaction and socialization, the watched being both objects of information and subjects of communication, the watchers assuming the role of a pseudo-television audience trying to make sense of a reality Soap Opera which is both enlightening and imprisoning. It has been argued that operators and the Stars of CCTV reside within the wider ontology of control which pervades CCTV surveillance. Each group exercises, and is subject to, differing forms of this control. Yet, interactions with such an ontology create a range of ambiguous, often inadvertent, outcomes. For example, whilst symbolic power is institutionally and organisationally held by operators through their capacity to anonymously observe, acquire knowledge and define reality, a lack of physicality in the action unfolding, a limited and controlled gaze and a sense of authoritative and directional disempowerment emotionally frustrates the watchers, sometimes to the point of surrender. In reality, power in this arena is ambivalent. It remains permanently in flux, flowing back 
and fore between the two surveillance 'subjects' during interactive games of cat and mouse, the outcomes of which vary. Thus, the watchers and watched are locked within a mediated, disembodied and ambiguous battle with one another, and the wider system engulfing them. The two have developed a range of tactics for coping and dealing with their respective placements, such practices connecting them socially through the interaction and meaning both appear to apply to, on the one hand, televisual monitor and, on the other, CCTV camera. Indeed, strategies of control create unintended responses, some of which facilitate social and systemic integration, others creating social and systemic disintegration. Overall, the paper has shown the complex nature and composition of ontological control mechanisms and the need to be aware of struggle and agency taking place within both the centres and peripheries of structural control.

Detailed qualitative research with the watched, however, is now urgently required, as only through such investigation will scholars be able to better discern whether the behaviours presented in this paper amount to conscious rational tactics, or subconscious survival methods. We may find it is both, or perhaps neither. Either way, more needs to be known about how surveillance is socially and psychologically experienced by those under its gaze. Conducting research of this nature, however, will present the researcher with a host of practical (legal), scientific (authenticity) and moral (ethical) problems. Rather like trying to associate with and research stars from the 'silver screen', access and research may be challenging. However, securing such entrée, contact and understanding will mean that surveillance scholars are better placed to empirically assess the existence, effectiveness and subjective value of 'street tactics' and, more theoretically, document the ways in which institutionally-created structural power strategies and forces are experienced, countered, subverted and redefined by the (relatively) powerless.

\section{References}

Ball, K. S. (2001) 'Situating workplace surveillance: ethics and computer based performance monitoring', Ethics and Information Technology, 3(3): 211-223.

Ball, K. S. (2003a) 'Categorizing the workers: electronic surveillance and social ordering in the call centre', in D. Lyon (ed.) Surveillance as Social Sorting: Privacy, Risk and Digital Discrimination. London: Routledge.

Ball, K. S. (2003b) ‘The Labours of Surveillance’, Surveillance and Society, 1(2): 125-137.

Bannister, J., N. Fyfe and A. Kearns (1998) ‘Closed Circuit Television and the City’, in C. Norris, J. Moran and G. Armstrong (eds), Surveillance, Closed Circuit Television and Social Control. Aldershot: Ashgate.

Bauman, Z. (1998) Work, consumerism and the new poor. Buckingham: Open University Press.

Biressi, A. and H. Nunn (2005) Reality TV: Realism and Revelation. London: Wallflower Press.

Botello, N. A. (2007) ‘An Orchestration of Electronic Surveillance: A CCTV Experience in Mexico’, unpublished paper, Universidad Autónoma del Estado de México.

Brubaker, R. (1984) The Limits of Rationality: An Essay on the Social and Moral Thought of Max Weber. London: Allen and Unwin. 
Cohen, S. and L. Taylor (1992) Escape Attempts: The Theory and Practice of Resistance to Everyday Life. London: Routledge.

Coleman, R. (2004) 'Reclaiming the Streets: Closed Circuit Television, Neoliberalism and the Mystification of Social Divisions in Liverpool, UK’, Surveillance and Society, 2(2/3): 293-309.

De Certeau, M. (1984) The Practice of Everyday Life. London: University of California Press.

Deleuze, G. (1990) 'Post-scriptum sur les sociétés de contrôle’, L'autre journal 1; trans M. Joughin (1992) 'Postscript on the societies of control', October 59: 3-7.

Denzin, N. K. (1995) The Cinematic Society: the voyeur’s gaze. London: Sage.

Douglas, M. (1991) Purity and Danger: An Analysis of the Concepts of Pollution and Taboo. London: Routledge.

Dubbeld, L. (2003) 'Observing bodies. Camera surveillance and the significance of the body’, Ethics and Information Technology, (5): 151-162.

Dubbeld, L. (2005) 'The Role of Technology in Shaping CCTV Surveillance Practices’, Information, Communication \& Society, 8(1): 84-100.

Fielding, N. (2001) 'Ethnography’, in N. Gilbert (ed.) (2001) Researching Social Life. London: Sage Publications.

Fonio, C. (2007) 'Surveillance and Identity: towards a new anthropology of the person', Paper presented at the British Sociological Association Annual Conference, London on $13^{\text {th }}$ April 2007.

Foucault, M. (1977) Discipline and Punish: The Birth of the Prison. London: Penguin Books.

Gadamer, H. G. (1979) Truth and Method. London: Sheed and Ward.

Garfinkel, H. (1967) Studies in Ethnomethodology. Englewood Cliffs, N.J.: Prentice-Hall.

Garland, D. (2001) The Culture of Control: Crime and Social Order in Contemporary Society. Oxford: Oxford University Press.

Gauntlett, D and A. Hill (1999) TV Living: Television, Culture and Everyday Life. London: Routledge.

Giddens, A. (1984) The Constitution of Society. Cambridge: Polity Press.

Giddens, A. (1990) The Consequences of Modernity. Stanford: Stanford University Press.

Gill, M and A. Spriggs (2005a) 'Assessing the impact of CCTV', Home Office Research Study 292. London: Home Office Research, Development and Statistics Directorate.

Gill, M. et al. (2005b) ‘Control room operation: findings from control room observations’, Home Office Online Report, http://www.homeoffice.gov.uk/rds/pdfs05/rdsolr1405.pdf

Glaser, B. G. and A. Strauss (1967) The Discovery of Grounded Theory. New York: Aldine de Gruyter.

Goffman, E. (1959) The Presentation of Self in Everyday Life. London: Penguin Books

Goffman, E. (1961) Asylums: essays on the social situation of mental patients and other inmates. New York: Doubleday. 
Goffman, E. (1967) Interaction Ritual: Essays in Face-to-Face Behaviour. Chicago: Aldine Publishing Company

Goffman, E. (1971) Relations in Public: Microstudies of the Public Order. New York: Basic Books.

Goffman, E. (1974) Frame analysis: An essay on the organization of experience. Harmondsworth: Penguin.

Goold, B. (2003) 'Public Area Surveillance and Policing: The Impact of CCTV on Police Behaviour and Autonomy’, Journal of Surveillance and Society, 1(2): 191-203.

Goold, B. (2004) CCTV and Policing: Public Area Surveillance and Police Practices in Britain. Oxford: Oxford University Press.

Graham, S. and S. Marvin (1996) Telecommunications and the City: electronic spaces, urban places. London: Routledge.

Gray, A. (1992) Video Playtime: the gendering of a leisure technology London: Routledge.

Helten, F. and B. Fischer (2003) 'Video Surveillance on Demand for Various Purposes? Berlin Shopping Malls as Socio-technical Testbeds for CCTV’, Working Paper No.11, http://www.urbaneye.net/results/ue_wp11.pdf

Helten, F. and B. Fischer (2004) 'Reactive Attention: Video Surveillance in Berlin Shopping Malls', Surveillance and Society, 2(2/3), pp323-345.

Hill, A. (2005) Reality TV: Audiences and Popular Factual Television. London: Routledge.

Latour, B. (1999) Pandora's Hope: Essays on the Reality of Science Studies. Cambridge, Massachusetts: Harvard University Press.

Latour, B. (2005) Reassembling the Social: An Introduction to Actor-Network-Theory. Oxford: Oxford University Press.

Lockwood, D. (1964) 'Social integration and system integration', in Z. Zollschan and W. Hirsch (eds) Explorations in Social Change. London: Routledge and Kegan Paul.

Lomell, H. M., A. Rudinow Saetnan and C. Wiecek (2003) 'Flexible Technology, Structured Practices: Surveillance operation sin 14 Norwegian and Danish organisations’, Working Paper No.9, http://www.urbaneye.net/results/ue_wp9.pdf

Lomell, H. M. (2004) 'Targeting the Unwanted: Video Surveillance and Categorical Exclusion in Oslo, Norway', Surveillance and Society, 2(2/3): 346-360.

Loveday, K. and M. Gill (2003) 'The Impact of Monitored CCTV in a Retail Environment: What CCTV Operators Do and Why’ in M. Gill (ed.) CCTV. Leicester: Perpetuity Press Ltd.

Lyon, D. (1994) The Electronic Eye: The Rise of Surveillance Society. Minneapolis: University of Minnesota Press.

Lyon, D. (2001) Surveillance Society: Monitoring Everyday Life. Buckingham: Open University Press.

Lyon, D. (ed.) (2003) Surveillance as Social Sorting: Privacy, Risk and Digital Discrimination. London: Routledge.

McCahill, M. (2002) The Surveillance Web: The rise of visual surveillance in an English city. Cullompton: Willan Publishing. 
McCahill, M. and C. Norris (2003) 'CCTV Systems in London: Their Structures and Practices’, Working Paper No. 10, http://www.urbaneye.net/results/ue_wp10.pdf.

Malinowski, B. (1922) Argonauts of the Western Pacific: an account of native enterprise and adventure in the Archipelagoes of Melanesian New Guinea. London: Routledge.

Manis, J. and B. Meltzer (1978) Symbolic Interaction: A Reader in Social Psychology. Boston: Allyn and Bacon.

Newburn, T. and S. Hayman (2001) Policing, Surveillance and Social Control: CCTV and Police Monitoring of Suspects. Cullompton: Willan Publishing.

Neyland, D. (2006a) 'Moving Images: The Mobility and Immobility of 'Kids Standing Still', Sociological Review, 54(2): 363-81

Neyland, D. (2006b) Privacy, Surveillance and Public Trust. London: Palgrave-Macmillan.

Norris, C. and G. Armstrong (1997) The Unforgiving Eye: CCTV Surveillance in Public Space. Hull: University of Hull.

Norris, C. and G. Armstrong (1998) 'Power and Vision’, in C. Norris, J. Moran and G. Armstrong (eds) (1998) Surveillance, Closed Circuit Television and Social Control. Aldershot: Ashgate.

Norris, C. and G. Armstrong (1999) The Maximum Surveillance Society: The Rise of CCTV. Oxford: Berg.

Norris, C. and M. McCahill (2006) 'CCTV: Beyond Penal Modernism', The British Journal of Criminology, 46(1): 97-118.

Reeve, A. (1998) 'The Panopticisation of Shopping: CCTV and Leisure Consumption', in C. Norris, J. Moran and G. Armstrong (eds), Surveillance, Closed Circuit Television and Social Control. Aldershot: Ashgate.

Scott, J. C. (1985) Weapons of the Weak: Everyday Forms of Peasant Resistance. New Haven: Yale University Press.

Scott, J. C. (1990) Domination and the Arts of Resistance: Hidden Transcripts. New Haven: Yale University Press.

Smith, G. J. D. (2004) 'Behind the Screens: examining constructions of deviance and informal practices among CCTV control room operators in the UK', Surveillance and Society, 2(2/3): 376-395.

Smith, G. J. D. (2007) 'The night-time economy: exploring tensions between agents of control’, in R. Atkinson and G. Helms (eds), Securing an Urban Renaissance: Crime, Community and British Urban Policy. Bristol: The Policy Press.

Smith, G. J. D. (forthcoming, 2008a) 'Who Would Be A CCTV Operator? Mapping the human-technology interaction and the social impacts of systems of surveillance on their operators', in K. F. Aas, H. O. Gundhus and H. M. Lomell (eds) Technologies of Insecurity: The surveillance of everyday life. London: Routledge-Cavendish.

Smith, G. J. D. (forthcoming, 2008b) 'Rooms without doors? Researching 'closed settings' - getting in, getting out', in L. Hempel and O. Svenonius (eds) The New Surveillance. Frankfurt: Suhrkamp Verlag.

Walby, K. (2005) 'Institutional Ethnography and Surveillance Studies: An Outline for Inquiry', Surveillance and Society, 3(2/3): 158-172. 